\title{
Applying Global Models of Teacher Develop- ment to Improve Student Outcomes: Insights from a Teacher Development \& Leadership Program in Qatar
}

Corresponding Author: Seungah S. Lee seungah@stanford.edu

Submitted: March 31, 2020

Accepted: January 5, 2021

Published: 1 July 2021

Production and Hosting by Knowledge $\mathrm{E}$

(c) Seungah S. Lee and Leena Zahir. This article is

distributed under the terms of the Creative Commons

Attribution License, which permits unrestricted use and redistribution provided that the original author and source are credited.

Managing Editor:

Natasha Mansur

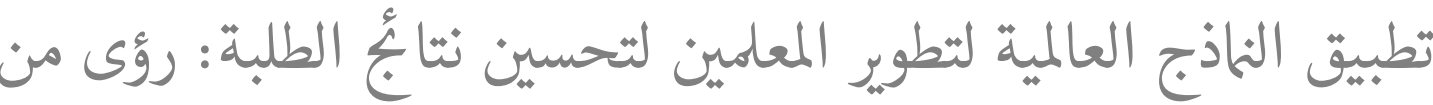

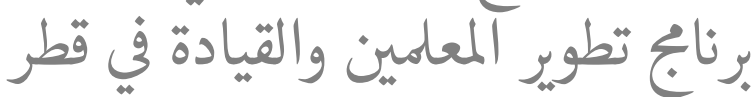

\section{Seungah S. Lee ${ }^{1}$ and Leena Zahir ${ }^{2}$}

${ }^{1}$ Stanford University, Stanford, CA, United States

${ }^{2}$ Independent Researcher, Doha, Qatar

ORCID:

Seungah S. Lee: https://orcid.org/0000-0003-4391-7049

Leena Zahir: https://orcid.org/0000-0003-1449-6767

\section{Abstract}

This paper aims to examine the relationship between progressive teaching practice and student academic and non-academic outcomes. The teacher development and leadership (TDL) program is a Qatari teacher development program that is a part of a wider global network (called "Global Network") that aims to expand educational opportunities through teacher development with its roots in the United States. (Names of organizations have been changed for anonymity). The training model of TDL program is based on six themes: (1) orientation to student vision, (2) ongoing reflection to improve practice, (3) setting high expectations for students, (4) ensuring content rigor and mastery in students, (5) fostering positive culture and learning environment, and (6) building positive relationships with students. We used a dataset that includes aggregate student- and teacher-level data from 136 classrooms (with 2,087 students) of 41 teachers between 2015 and 2017 to understand the relationship between teacher effectiveness and student outcomes. We found that establishing a positive rapport with students, practicing ongoing reflection, and internalizing learning are associated with higher academic achievement. We also found that incorporation of student vision for teaching practice is correlated with students having more positive attitude toward learning.

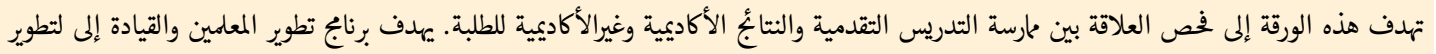

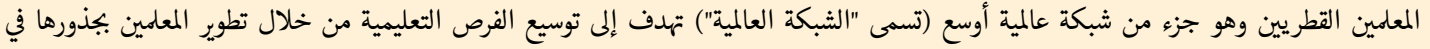

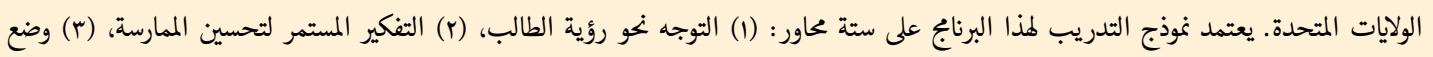

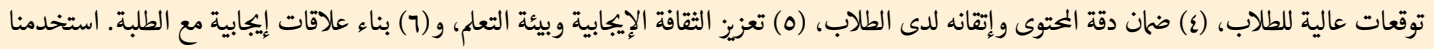

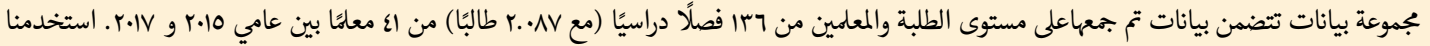

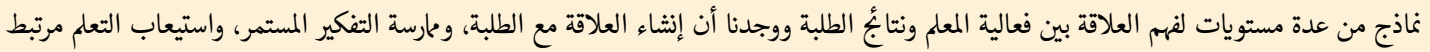

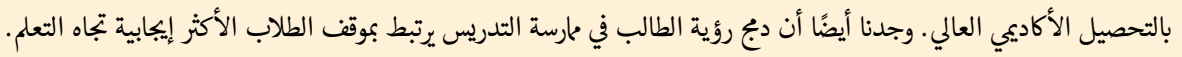

\section{G OPEN ACCESS}


الكالمات المفتاحية: فعالية المعلم، التعليم المتقدم، تعليم المعلمين، قطر، الخليج العربي 


\section{Introduction}

Recognizing the importance of diversifying the economy and working toward a knowledge-based economy, Arabian Gulf countries (Bahrain, Kuwait, Oman, Qatar, Saudi Arabia, and the UAE) have placed human capital development and education at the forefront of their national development agendas (Al Thani, 2012). To improve their respective education systems, Arabian Gulf states have largely focused their reform efforts on making investments in "hard" infrastructure, better managing overall performance of school systems, and increasing the number of teachers to promote student achievement (Barber et al., 2007).

Despite such efforts, student achievement in the Arabian Gulf has continued to be significantly below international averages, as evidenced by results from international assessments such as PISA, PIRLS, and TIMMS (Mullis et al. 2012; OECD, 2014). (Of note, while Qatar has participated in PISA since 2006, the United Arab Emirates began participating in 2015 and Saudi Arabia in 2018. Kuwait, Bahrain, Oman are not PISA participants. All GCC countries, however, participate in the PIRLS assessment, and their national average attainment scores were below the international intermediate benchmark threshold in 2011 and 2016). In fact, concerns about the consequences for the Qatari education system resulting from students' low performance on international exams led the Qatari government to embark on educational initiatives and reforms (Nasser \& Romanowski, 2011). Qatar's leadership commissioned RAND corporation to examine Qatar's education system and lead K-12 reform in the 2000s (Brewer et al., 2007). RAND found that teachers did not appeared to receive adequate training and professional development prior to reforms and that much of the training they received was often decoupled from reality in the classroom (Zellman et al., 2009). Moreover, despite the efforts to improve teacher quality and substantial national investment in professional development initiatives as a part of the reform movement, concerns remain about the quality of the educational staff and the subsequent impact on student learning (Abu-Tineh \& Sadiq, 2018; Brewer et al., 2007).

Given the persistent challenges around teacher quality and relatively low student learning outcomes, an independent nonprofit organization, called "TDL" for the purposes of this paper, was inaugurated in 2013 by H.E. Sheikha Hind bint Hamad Al-Thani to be a part of the solution. TDL is affiliated with an international NGO (referred to as "Global Network" in this paper) that functions as a global network of independent organizations that work to expand educational opportunities through teacher development and reinvest talented local leaders into Qatar's independent school system through a two-year teaching and leadership development program. An underlying teaching philosophy that shapes Global Network and TDL is moving away from traditional teaching and rote memorization toward more progressive and constructivist teaching, which is a shift that has been observed throughout the world to improve teaching and learning practice in classrooms and schools (Sherman, 2009).

Focusing on employing progressive and constructivist pedagogy that are studentcentered in training and developing teachers is not necessarily novel. In fact, professional development activities provided as a part of the reforms in Qatar, often provided 
by international consultants, included topics such as use of technology, strategies for teaching students with different abilities, and various approaches to assessment that were also based on more progressive, student-centered, project-based pedagogical approaches (Brewer et al., 2007). Nevertheless, the TDL case is unique and interesting in that it takes a non-traditional model of teacher recruitment, placement, and training that is based on a teacher training and development model that originated in the United States for contexts facing education inequity and contextualizes and adapts it to the Qatari context.

This paper examines the case of TDL and seeks to answer the following questions. How do pedagogical approaches and teacher actions based on the TDL/Global Network model influence student outcomes and attitude toward learning? To what extent does adoption of an international NGO's teacher training and development model yield student outcomes as expected and predicted by lessons learned from other contexts applying the same model? (see Ahmann (2015), Cumsille and Fiszbein (2015), Ellis et al. (2015), and McConney and Woods-McConney (2012) for studies that examine the scalability, impact, and efficacy of the Global Network model in context to various countries). More specifically, this paper observes the relationship between progressive teaching practice, academic achievement, and student motivation to learn in the Qatari independent school context. It examines TDL classrooms in Qatar's independent preparatory schools (grades 7-9), as these classrooms consistently adopt progressive teaching over traditional teaching by virtue of the teacher training and development model of the organization.

Contextualizing a global teacher development model for the Qatari context and attempting to understand the extent to which it is generalizable to non-Western contexts is valuable given the unique nature of the challenges facing the Qatari context. The independent schools where TDL places its teachers are not underserved in the traditional sense of lacking resources or being affected by low levels of socioeconomic status. However, families who send their children to Qatar's public schools, which are gender segregated, tend to be more conservative than those who send their children to private schools (Badry \& Wiloughby, 2016). In this sense, there is a public-private divide in Qatar along ideological lines. Despite huge investments in physical (e.g., facilities, technology) infrastructure and introduction of more student-centered pedagogy, statefunded independent school students seem to be faring worse than their private school counterparts in terms of both academic achievement and engagement/motivation for learning (Author, 2016; SESRI, 2013). The underperformance of public schools is further highlighted in the comparatively sub-par performance of their students in international standardized tests such as the PISA compared to private school students (Cheema, 2015).

Therefore, in addition to contributing to literature on how teacher actions and pedagogical approaches influence student outcomes, this paper builds on previous studies that examined whether or not international models of education are indeed appropriate and effective for a non-Western, more conservative Qatari society context. Studies that have examined the adoption of global best practices in Qatar have typically focused on the unpreparedness of the education system to implement recommended changes 
and the gaps that remain since RAND's involvement (see Al-Fadala (2015), Alkhater (2016), Nasser (2017); Ellili-Cherif et al. (2012) for examples). This paper contributes to this literature by examining the direct results of the implementation of a Western model of teacher training and development "as-is" in the Qatari context as opposed to broad recommendations for the education system as a whole based on Western education systems.

\section{Background}

\subsection{TDL and the global network}

TDL is an independent partner organization of the Global Network that works in partnership with local governments and ministries of education to place teachers in independent schools in Qatar (At the time of the study, all public schools were independent schools, that is, state-funded schools with the autonomy to recruit teachers and staff). It seeks to improve quality education in Qatar by empowering young talent to become transformational leaders in the classroom, school, and community (TDL, 2015). More specifically, it seeks to improve students' academic and non-academic learning outcomes, improve their attitude toward education and learning, and motivate them to aspire and achieve through their teaching fellows. To do so, TDL employs an innovative, student-centered pedagogy that has its roots in constructivism and situated learning based on the Global Network model as an attempt to depart from the traditional teaching model and transform the culture of teaching in Qatar.

"Global Network" is an international NGO that facilitates a "growing network of 53 independent partner organizations" to develop leadership in classrooms and communities to ensure all children can fulfill their potential (Global Network, 2019). All partner organizations follow a similar model of a two-year teaching program targeting recent graduates and young professionals outside the education field (i.e., who are not graduates of schools of education or trained educators). These individuals are recruited to teach in low-achieving schools for two years during which they receive ongoing support with their teaching practice as well as for creating system-level change in their educational contexts. (All information about "Global Network" and "TDL" are based on information provided on their respective websites, internal documents, and conversations with staff). By expanding the network of independently run, partner organizations and providing technical support to these organizations, Global Network aims to build a strong movement to lead necessary change in the educational system from both within and outside the classroom and address issues of education equity through systemic change.

Adopting Global Network's model, TDL recruits young talent from universities and the private sector to participate in a two-year teaching and leadership development fellowship program. Part of the rationale for why TDL adopts Global Network's model and actively recruits young talent, especially local, Qatari talent, from the private sector is that one of the objectives of TDL is to raise the profile of the teaching profession and encourage more young talent to pursue teaching as a career path (TDL, 2015). 
(Teaching is not perceived as an elite, prestigious profession throughout much of the world (Hoyle, 2001; Ingersoll \& Collins, 2018), and this is also the case for Qatar). Candidates undergo a rigorous assessment process prior to selection where they are evaluated on their subject knowledge (Math, Science, or English), interest in education, teaching skills, reflection, and teamwork, among other competencies. Once they are selected, they become "fellows." The "fellows," or TDL teachers, are then trained for six weeks in areas such as encouragement of inquiry-based/project-based learning in the classroom, group work, differentiation, and scaffolding by veteran teachers in Qatar's independent education system, who serve as teacher coaches. (TDL teachers are also trained and assessed on other areas that are found in Steven Farr's Teaching as Leadership framework, namely, setting ambitious goals, investing students and families, planning purposefully to achieve student vision for success, executing plans effectively, continuously increasing effectiveness, and working relentlessly to navigate challenges (Farr, 2010)). Following this pre-service training period, recruits are then placed to teach either English, Math, or Science to grades 7-9 of Qatar's state-funded preparatory independent schools (TDL, 2015).

The selection of partner independent schools in the Qatari context is in line with the Global Network's approach of infusing "new blood" into schools that are characterized as underserved or low achieving under the belief that such a disruption would result in creative solutions to challenges faced by these schools. This is based on TDL's theory of change that introducing teachers who are trained in more constructivist pedagogies, compared to pedagogy that encourages rote learning as it is commonly practiced in Qatar's independent schools, would facilitate improved student learning outcomes (TDL, 2016a).

In fact, at the core of Global Network, and subsequently TDL's, teacher training and development model is an approach influenced by Piagetian constructivism and social constructivism (see Ackerman (2001), Gredler (2009), and Papert (2000) The details of reference Papert (2000) for constructivist learning theories). This approach emphasizes student-centered strategies that promote student leadership and ownership of the learning experience and empowers teachers to facilitate students' active role in the construction of meaning. Furthermore, the teacher training models of both TDL and Global Network incorporate elements of culturally relevant pedagogy through its emphasis on employing value-based, contextualized learning to achieve academic excellence in students. A culturally relevant pedagogy is one which promotes academic success and cultural competence and empowers students to understand and critique lived social inequities (Ladson-Billings, 1994, 1995a, 1995b). Therefore, development of both a contextualized vision and teaching practices based on a deep understanding of the context as well as the integration of cultural referents in teaching is highly emphasized and serves as a core part of TDL's theory of teacher development. In fact, throughout the program, TDL teachers are highly encouraged to develop a contextualized student vision and continuously root their teaching practice on their respective student visions to improve student academic and non-academic outcomes by reflecting on their practice.

In essence, TDL's teacher training and development philosophy and approach can be summarized as being comprised of the following elements: (1) orientation to student 
vision; (2) ongoing reflection to improve practice; (3) setting high expectations for students; (4) ensuring content rigor and mastery in students; (5) fostering positive culture and learning environment; and (6) building positive relationships with students (TDL, 2016a).

This is not to say that non-TDL teachers in Qatar's public schools are not trained in these areas. Ministers of Education throughout the Arab Gulf, including that in Qatar, do provide training on student-centered pedagogical methods in accordance with national teacher professional standards (Nasser, 2017; Qatar Ministry of Education, 2015). However, despite the provided training, much of the teaching practices observed in Qatar's public schools engage in traditional methods such as rote memorization and repetition that evoke behaviorist and reciprocal theories of learning (see Gredler (1997), Skinner (1986), and Thorndike (1913) for behaviorism). Furthermore, quasi-experimental studies examining effectiveness of teacher training on student-centered pedagogical methods suggest that "reforms related to student-centered instruction in Qatar are not yet in place and unlikely... to foster student self-regulation or productive disciplinary engagement" (Knight et al., 2014, p. 42).

Another shortcoming of teacher training on student-centered pedagogy is the lack of additional, ongoing, and targeted coaching and feedback (Knight et al., 2014). It cannot be said that TDL teachers do not engage in traditional ways of teaching such as rote memorization and teacher-centered pedagogy. Moreover, it cannot be assumed that TDL teachers are highly proficient practitioners of student-centered, constructivist pedagogy that situates learning in a manner that is highly relevant and relatable for students. However, what distinguishes TDL teachers from other teachers in Qatar's independent schools is that TDL teachers undergo intensive and ongoing pedagogical training and professional development throughout summer months and the academic year (TDL, 2016a). Furthermore, this training not only adopts an explicitly progressive, constructivist epistemology but also emphasizes teacher orientation to student vision and ongoing reflection to support teaching practice. What this means is that TDL mitigates potential reasons for why student-centered pedagogy may not be implemented in Qatar's public-school classrooms for the TDL teachers through its ongoing teacher training and development program. In fact, surveys and interviews with school administrators that were conducted as a part of this study suggest that TDL teachers, on average, employ student-centered teaching strategies and constructivist pedagogical models more than non-TDL teachers.

In the following sections, this paper examines various elements of TDL's approach to teaching and teacher development to understand which TDL characteristics and actions predict student academic and non-academic outcomes. Of the six core areas of TDL's teaching and teacher development model, the paper is most interested in the ongoing reflection, student vision, and captivating (i.e., engaging students by making learning relevant) aspects, as these aspects are explicitly stressed by TDL but not addressed by Qatari independent schools' professional development sessions. It is hypothesized that these three aspects, along with the other three aspects, would positively predict increase in academic achievement and improve non-academic student outcomes, that 
is, students' attitude toward learning and their learning behavior and aspiration to attend university.

\section{Data and Methodology}

\subsection{Data}

Our analysis draws from TDL's classroom-level student surveys, diagnostic test scores, and teacher observation rubric scores, in addition to metadata on teacher characteristics. The surveys and diagnostic tests were administered by the TDL teachers, but the authors of this paper oversaw the administration and data collection process. The dataset includes aggregate student- and teacher-level data from 136 classrooms for 41 teachers between 2015 and 2017. This is based on individual student-level data for 2,087 students. All teachers during the study period taught grades 7 and 8 students who were aged 11-14 years. Independent schools in Qatar are gender-segregated and teachers teach students belonging to their respective genders. The classroom-level student survey data comes from two different surveys: (1) the Student Mindset Survey, developed internally by TDL, and (2) the Student Tripod Survey, developed by Ronald Ferguson as part of the Measures of Effective Teaching Study (Ferguson, 2012). Both surveys and the diagnostic tests were administered by the TDL teachers in their respective classrooms and were later collected by the authors for analysis. Teacher observations were scored on a 5-point Likert scale based on TDL's internally developed teacher observation rubric that was modeled on its teaching and learning philosophy and wider Global Network model. (The authors were involved in the process of developing the teacher observation rubrics with the TDL team and spent time training staff to use the tools. The authors engaged in some observations with the TDL teacher coaches to ensure that all teachers were being assessed on the rubric consistently.) The rubric asks the teacher coaches to score TDL teachers across various indicators, including teacher presence, setting high expectations for students, flow of lesson, articulating student vision, constructing learning experiences to world outside the classroom, differentiating instruction and teaching for student ability, and engaging in ongoing reflection (This is not an exhaustive list of all areas observed in the TDL observation rubric.) (TDL, 2016b).

The authors trained the TDL teachers on how to administer the surveys and diagnostic tests in their respective classrooms and then collected data for analysis. TDL teachers administered student mindset, tripod, and diagnostic tests in the beginning and end of the year as a pre- and posttest in Qatar. The surveys and tests were administered in students' regular classrooms, using a standard protocol. Confidentiality was maintained for all data. Given that surveys were administered in the beginning of the year and that students did not have any interaction with the teachers in previous years, student responses could not have been significantly influenced by the work of TDL teachers. It is also assumed that participating students' responses in these classrooms would have been no different from that if administered in non-teaching fellow classrooms. To ensure that teacher coaches were rating teachers in a consistent manner, the authors 
collaborated with TDL staff to train teacher coaches on the rubric and observation protocol and participated in teacher observations as well as with the teacher coaches.

Because the pre- and posttests were implemented anonymously, responses from the tests could not be matched to individual students but could be matched to the class to which the students belong. Therefore, student individual responses were aggregated at the classroom level. The classroom-level data reported the percentage of students who responded positively, that is, those who responded with 4 or 5 on a 5-point Likert scale.

\subsection{Methodology}

In Qatar's independent schools, students are assigned to a class and are required to take all subjects together as a class. Subject teachers take turns teaching their assigned classes throughout the day. In this sense, classrooms are nested within teachers. Therefore, hierarchical linear modeling is employed to examine the relationship between classroom-level student outcomes and teacher practices. A multilevel hierarchical model accounts for the correlated errors at the teacher level, which violates assumptions necessary for ordinary least squares (OLS) regression (Raudenbush \& Bryk, 2002).

The model is given by $y_{i j k}=\beta_{0}+\beta_{1} X_{1 i j}+\beta_{2} X_{2 j}+v_{j}+e_{i}$, where:

$i=$ Classroom

$j=$ Teacher

$k=$ End of year scores on student academic and non-academic outcome (i.e., learning behavior and attitude toward school) measures

$y_{i j}=$ The score that classroom $i$ belonging to teacher on each outcome variable $k$

$X_{1}=$ A vector of classroom-specific variables, including pretest scores

$X_{2}=$ A vector of teacher-specific variables

$v_{j}=$ Teacher-level errors, which are assumed to be normally distributed

$e_{i}=$ Classroom-specific errors

\subsection{Dependent variables}

The outcome variables of interest are as follows: (1) student academic achievement, (2) student's overall attitude toward learning/school, (3) student's learning behavior, and (4) student's aspiration to enroll in university. These variables were selected because these are student outcomes of interest for TDL and because previous study (Lee, 2016) on Qatar's grade-7 and 8 independent school systems have shown that students have low motivation for learning and subsequently do not engage actively in the learning process.

Student academic achievement is measured by diagnostic test scores across three subjects that TDL teaching fellows teach, that is, Math, Science, and English. Student attitude toward learning and learning behavior are measured by factor analysis, with generated factor scores based on items that load highly on a single factor (with Eigenvalues $>1$ ) and thus constitute a measure on student mindset survey results. These two 
outcome variables, that is, factor score that measures student attitude toward school and student learning behaviors, were constructed from student mindset survey question items. (The student mindset surveys were developed by the authors in coordination with the training and support team at TDL.) Two continuous outcome variables that measure each of the two outcome measures were constructed based on the latent variables identified by factor analysis. A complete list of the individual survey items, their prevalence in the sample, and the extent to which each item loads onto the factors are included in Table 1.

\section{Table 1}

Mean and rotated factor loadings for student mindset survey items

Survey items
Strive to be one of the best
students in my class
Do more than what is expected in
assignments
Give answers in class
Ask questions in class
Come up with different ways to
solve problems
Strive to get better at schoolwork
Talk to friends and family about
what was learned in school
Look forward to going to school
Motivated to go to school
everyday
Think what is being learned in
class is useful
Believe that education is important

\begin{tabular}{|l|}
\hline Mean \\
\hline 0.7625 \\
\hline 0.7035 \\
\hline 0.7437 \\
\hline 0.4513 \\
\hline 0.6265 \\
\hline 0.8692 \\
\hline 0.4981 \\
\hline 0.5516 \\
\hline 0.5538 \\
\hline 0.8048 \\
\hline 0.9121
\end{tabular}

\begin{tabular}{|c|c|}
\hline \multicolumn{2}{|c|}{ Rotated factor loadings } \\
\hline Learning behavior & Attitudes toward school \\
\hline 0.8238 & 0.2276 \\
\hline 0.6755 & 0.352 \\
\hline 0.7541 & -0.0219 \\
\hline 0.5784 & 0.2204 \\
\hline 0.6435 & 0.1323 \\
\hline 0.6737 & 0.2861 \\
\hline 0.45 & 0.5047 \\
\hline 0.1886 & 0.844 \\
\hline 0.26 & 0.8569 \\
\hline 0.609 & 0.4475 \\
\hline 0.0856 & 0.6573 \\
\hline
\end{tabular}

The rotated factor loadings can be interpreted as the correlation between an item and each latent factor. Six student mindset survey items load onto a distinct latent variable we term "student learning behavior," and these items do not load strongly onto the other factor. Five of the six student mindset survey items load onto a distinct latent variable we term "student attitude toward learning/school," and these items do not load strongly onto the other factor. A check of internal consistency of each factor was satisfactory. Cronbach's alpha for student learning behavior factor was 0.833 and that for the student attitude for learning factor was 0.802 , both at values above the standard threshold of 0.7. The final outcome variable of interest, that is, aspiration to go to university, is based on the Student Mindset Survey. Given that the data were aggregated at classroom level, this indicator reports the percentage of students in the class who indicate that they aspire to enroll in university. 


\subsection{Independent and control variables}

Given that the paper is interested in the effect of teacher behaviors and competencies on student outcomes, independent variables are generated from Student Tripod Surveys and teacher observation rubric scores. Global Network's Student Tripod Survey is a tool developed by Dr Ronald F. Ferguson of Harvard University in collaboration with Cambridge Education to capture students' attitude toward their teacher and classroom environment (Ferguson, 2012). Administered at the beginning and end of every academic year, the Student Tripod Survey provides student feedback-based insight into seven categories for measuring teacher effectiveness, as identified by the Gates Foundation Measures of Effective Teaching study. The seven categories are as follows: care, confer, challenge, captivate, clarify, consolidate, challenge, and control (Ferguson, 2012). Each of the seven categories take on a composite percentage value of students responding positively to individual questions (asked on a 5-point Likert scale) within the respective category.

The "care" variable captures questions (from the Student Tripod Survey) that asks students whether encouraging and supportive relationships are fostered by the teacher. The "confer" variable captures questions that ask students whether the teacher values a student's input and ideas. The "challenge" variable captures questions that ask students whether rigorous expectations are held. The "captivate" variable captures questions that ask students whether engaging learning environment is established. The "clarify" variable captures questions that ask students if teachers check for and ensure understanding. The "consolidate" variable captures questions that ask about whether teacher helps students fully internalize learning. The "challenge" variable captures questions that ask about whether the teacher holds rigorous expectations for their students. The "control" variable captures questions that ask about how the teacher manages their classroom and fosters a positive cultural and learning environment.

The TDL teacher observation rubric is extensive, and teachers are scored along various categories, including those that are highly correlated with the seven categories measured under the Student Tripod Survey. Therefore, the paper only observes observation rubric scores for items that are foundational to TDL's teaching and learning philosophy: commitment to student vision, ongoing reflection, differentiating instruction, and building student-teacher rapport. These observation rubrics are scored on a scale of 1 to 5 (where 1 = poor and $5=$ excellent). The scores were determined by the teacher coaches who oversee the TDL teachers.

Besides teacher's years of experience, gender of the classroom, and subject taught by the TDL teacher are also added as control variables. Qatar's independent preparatory schools are gender segregated. Therefore, though the gender variable is captured at the classroom-level, this variable implies that all students in a particular classroom were either all male or female. Descriptive statistics for the variables can be found in the Appendix (Table A1). 


\subsection{Limitations}

Available data are limited to TDL's teachers and their students in Qatar's independent preparatory schools; therefore, it is not possible to compare TDL teachers to non-TDL teachers in Qatar's independent schools in their effectiveness as evidenced by student outcomes. Furthermore, provided that both TDL and non-TDL teachers teach the same classes based on the subject area, it is difficult to isolate the effects of TDL teacher on student outcomes and make causal inferences given the lack of a comparison group. Therefore, we rely on pre- and posttest data to gain insights into how a teacher's actions and behavior may influence student outcomes. Student tripod surveys measure students' perception on teachers' actions on the seven categories, specifically for the TDL teacher teaching either English, Math, or Science to the students. It may be difficult for students to completely be able to differentiate the behavior of TDL teachers (i.e., for the student, the TDL teacher would be their Math, Science, or English teacher) from that of the other teachers. However, to aid the students to think about their Math, Science, or English teacher, students were asked to complete the Student Tripod Survey during the class period in which the TDL teacher taught (e.g., Math class). They were asked to answer the survey to the best of their abilities for that specific subject teacher (e.g., for Math (TDL) teacher during Math class period). Furthermore, we are interested in understanding how specific TDL/Global Network values such as sharing student vision with students and engaging in ongoing reflection had an influence on students' achievement and attitude toward learning. Given that we cannot ignore how other teachers and environmental factors may have influenced students' attitude toward learning and university aspirations, coefficient estimates for the student vision and ongoing reflection are likely to be overestimated. Nevertheless, the significance of these variables would suggest that teachers who articulated student vision and/or engaged in ongoing reflection likely had at least some influence on students' attitude and aspirations compared to those who did not engage in these teacher actions.

While considering analysis using this TDL dataset, however, it is important to note that student surveys and classroom observations are based on perceptions, which means that the evaluations and scores on these items are subjective and may vary from individual to individual. In fact, dependent variables measuring non-academic outcomes are based on self-reported student questionnaires. Although there is value in capturing student voice and understanding student perspectives, particularly as the scope of the study is focused on student mindsets and attitude, student responses are likely to be positively biased. With regard to teacher observation data, teacher trainers were trained on TDL's classroom observation protocol and engaged in further discussions as a team to ensure that teacher trainers are assessing teachers in a consistent manner.

Other limitations of this data are that the data sample is limited to a two-year time frame, the quality of which is inevitably dependent not only on conditions of the context of the given time but also on the specific characteristics of TDL teaching cohorts in these years and the grade-7 and 8 students taught in Qatar's independent schools. Of note, findings from this paper may be limited to and relevant for these groups of teachers and students and it should not be presumed that results would 
be similar for other groups of teachers and students, that is, those in private schools or in various levels of education. Another limitation is that the available data lack a comparison group. Therefore, causal inference cannot be made to understand whether the characteristics of TDL teachers compared to non-TDL teachers make a difference in students' academic and non-academic outcomes. Nevertheless, our findings provide important insights into the effects of teacher behavior and pedagogy on students' academic and non-academic outcomes in the Qatari context. However, this study should not be taken as an expansive and comprehensive study of the relationship between teacher behavior and student outcomes in Qatar. Further studies are recommended to be conducted in more classrooms, over a longer period, and in different contexts for more refined and robust insights into the effectiveness of teacher behavior and pedagogical approaches examined in this paper on improving student outcomes.

\section{Findings and Discussion}

Analysis begins with descriptive statistics of the difference between average class-level student outcomes between the beginning of the year (pretest) and the end of the year (posttest). Table 2 reports paired $t$-test results of post- and pretest scores of the outcome variables of interest.

Table 2

Descriptive statistics and paired sample t-tests for classroom outcomes

\begin{tabular}{l|c|c|c|}
\hline $\begin{array}{l}\text { Classroom-level student } \\
\text { outcomes }\end{array}$ & Pretest & Posttest & Difference \\
\hline Subject Diagnostic Test & M (SD) & M (SD) & M (SD) \\
\hline Attitude toward Learning/School & $0.3567(0.0147)$ & $0.4969(.0233)$ & $0.1402(0.0167)^{* * *}$ \\
\hline Demonstrated Learning Behavior & $0.6571(0.0095)$ & $0.5803(0.0087)$ & $-0.0769(0.0088)^{* * *}$ \\
\hline Aspiration to Attend University & $0.9212(0.0071)$ & $0.9113(0.0075)$ & $-0.0099(0.0075)^{*}$ \\
\hline *** $<<0.001 \cdot{ }^{* *}$ (0.0082) & & $0.6445(0.0092)$ & $-0.4811(0.0088)^{* * *}$ \\
\hline
\end{tabular}

Descriptive analysis shows that between the beginning and the end of the school year, TDL classroom-level academic achievement as measured by diagnostic tests increased, whereas TDL classroom-level students' attitude toward learning, demonstrated learning behavior, and aspiration to attend university decreased over the course of the academic year. This is surprising, as one would expect an increase in all areas from the beginning to the end of the year. The negative results may be due to several factors such as TDL teachers lacking teaching skills to effectively improve non-academic aspirations and outcomes of students as young, inexperienced teachers. In addition, the social constructivist methods employed by TDL, compared to the more traditional, behaviorist approach, may not be as effective in Qatar's public schools as TDL initially conceived. Alternatively, student factors may contribute to the decline, as students simply may be demotivated or unmotivated to engage with school and learning at the end of the school year compared to the beginning of the school year. 
Examining teacher characteristics, especially teacher actions, in more detail could provide insights into whether there are certain teacher behavior and actions that positively (or negatively) predict student academic and non-academic learning outcomes. In fact, understanding directionality of various teacher actions and behaviors may allow TDL to further understand what "works" and what "doesn't work" in improving student outcomes and subsequently inform TDL's model of teacher training and development. Moreover, although the data and cases are limited to that of the TDL context, findings and insights from this analysis could be of value to educators, teacher trainers, and practitioners in other Qatari contexts, and potentially even in the wider Arab Gulf context, as the region not only shares a similar education development trajectory but also faces similar challenges of low student academic achievement, lack of student motivation to learn, and low levels of student engagement in the classroom (Barber et al., 2007; De Boer \& Turner, 2007). Results from this study should not be assumed to be representative of the entire education landscape of Qatar or the wider Arabian Peninsula. The following analysis examines which classroom and teacher characteristics predict student academic and non-academic outcomes.

Table 3 shows multilevel regression results for the four dependent variables, that is, the end-of-year classroom-level scores (posttest) on student academic achievement as measured by subject diagnostic test, students' overall attitude toward learning/school, students' learning behavior, and students' aspiration to enroll in university.

\subsection{Academic achievement}

Model 1 shows multilevel regression results for end-of-year subject-level diagnostic tests (posttest results). At the classroom level, both pretest scores and gender are significant predictors for end-of-year test scores. As expected, pretest scores are a significant predictor for posttest results, as it would be assumed that classroom with higher student test score averages at the beginning of the year would have higher end-of-year scores.

At the teacher level, regression results suggest that teacher actions positively associated with end-of-year test scores are establishing student-teacher rapport, practicing ongoing reflection on to improve own pedagogical practice, and internalizing learning for students. (Note: Consolidating learning entails summarizing information and drawing connections between new information and ideas discussed previously. Captivating students involves communicating ideas in an engaging manner by understanding students' needs, differentiating instruction, and drawing connections to real life and/or students' culture). In other words, classrooms with teachers that engage in these behaviors are associated with higher diagnostic test scores compared to their counterparts with teachers who do not engage in such behaviors. These results are not surprising since teachers are expected to be more likely to facilitate student learning in classrooms where teachers build rapport with the students and help students internalize curricular content in their respective subject areas through a variety of ways, including differentiating instruction, drawing connections to real life, having students explain concepts to each other, etc. (Bransford et al., 1999; Chi et al., 1994; Farr, 2010; Wiske, 1998). Furthermore, one would expect that teachers who apply ongoing reflection on their 


\section{Table 3}

Hierarchical linear model analysis of classroom-level student outcomes (For diagnostic test, all teacher practice scores are based on end-of-year scores. For non-academic outcomes, all teacher practice except that for student vision and reflection are end-of-year scores. Student vision and reflection for non-academic outcomes are beginning-of-year scores)

\begin{tabular}{|c|c|c|c|c|}
\hline & Diagnostic test & $\begin{array}{l}\text { Attitude toward } \\
\text { learning }\end{array}$ & $\begin{array}{l}\text { Learning } \\
\text { behavior }\end{array}$ & $\begin{array}{l}\text { University } \\
\text { aspiration }\end{array}$ \\
\hline & Model 1 & Model 2 & Model 3 & Model 4 \\
\hline \multicolumn{5}{|l|}{ Classroom predictors (level 1) } \\
\hline \multirow[t]{2}{*}{ Pretest } & $0.659^{* * *}$ & $0.181^{*}$ & $0.311^{* * *}$ & $0.297^{* *}$ \\
\hline & $(0.254)$ & $(0.103)$ & (0.0689) & $(0.120)$ \\
\hline \multirow[t]{2}{*}{ Male } & 0.000155 & $0.753^{*}$ & 0.305 & -0.0585 \\
\hline & $(0.0622)$ & $(0.428)$ & $(0.313)$ & (0.0379) \\
\hline \multicolumn{5}{|l|}{ Teacher predictors (level 2) } \\
\hline \multirow[t]{2}{*}{ Qatari } & 0.0185 & 0.227 & 0.000993 & 0.0241 \\
\hline & $(0.0532)$ & $(0.360)$ & $(0.268)$ & $(0.0317)$ \\
\hline \multirow[t]{2}{*}{ Years of experience } & 0.0269 & 0.271 & -0.0820 & -0.00936 \\
\hline & $(0.0767)$ & $(0.405)$ & (0.299) & $(0.0354)$ \\
\hline \multirow[t]{2}{*}{ Setting expectations } & $-0.136^{* * *}$ & $0.503^{*}$ & 0.138 & -0.0168 \\
\hline & $(0.0420)$ & (0.298) & $(0.223)$ & $(0.0263)$ \\
\hline \multirow[t]{2}{*}{ Differentiation } & -0.0334 & -0.248 & 0.389 & 0.0110 \\
\hline & $(0.0461)$ & $(0.344)$ & $(0.253)$ & (0.0299) \\
\hline \multirow[t]{2}{*}{ Student vision } & $-0.0673^{*}$ & $0.498^{* *}$ & 0.0454 & -0.0162 \\
\hline & $(0.0361)$ & $(0.221)$ & $(0.165)$ & (0.0196) \\
\hline \multirow[t]{2}{*}{ Student-teacher rapport } & $0.119^{* * *}$ & $-0.664^{* *}$ & $-0.371^{*}$ & $0.0490^{* *}$ \\
\hline & $(0.0362)$ & $(0.279)$ & $(0.206)$ & $(0.0244)$ \\
\hline \multirow[t]{2}{*}{ Ongoing reflection } & $0.324^{* * *}$ & -0.0325 & -0.548 & 0.0477 \\
\hline & $(0.109)$ & $(0.604)$ & $(0.452)$ & $(0.0534)$ \\
\hline \multirow[t]{2}{*}{ Care (Encourage) } & $-0.638^{*}$ & -2.201 & -0.885 & 0.0673 \\
\hline & $(0.362)$ & $(2.313)$ & (1.671) & $(0.194)$ \\
\hline \multirow[t]{2}{*}{ Consolidate (Internalize) } & $2.092^{* * *}$ & 1.302 & -1.583 & 0.329 \\
\hline & $(0.607)$ & (3.926) & $(2.973)$ & $(0.346)$ \\
\hline \multirow[t]{2}{*}{ Control (Classroom mgmt.) } & -0.445 & 0.652 & $2.311^{* *}$ & 0.00885 \\
\hline & $(0.286)$ & $(1.457)$ & $(1.042)$ & $(0.122)$ \\
\hline \multirow[t]{2}{*}{ Challenge (Rigor) } & $-1.353^{* *}$ & -4.184 & -1.060 & $-0.543^{*}$ \\
\hline & $(0.615)$ & (3.360) & $(2.498)$ & $(0.295)$ \\
\hline \multirow[t]{2}{*}{ Confer (Input) } & $-0.923^{* * *}$ & 3.814 & $4.898^{* * *}$ & 0.0573 \\
\hline & (0.348) & $(2.369)$ & (1.735) & (0.206) \\
\hline \multirow[t]{2}{*}{ Clarify (Understanding) } & 0.382 & -3.298 & 0.758 & 0.131 \\
\hline & (0.626) & (3.995) & $(2.951)$ & (0.347) \\
\hline \multirow[t]{2}{*}{ Captivate (Engage) } & 0.905 & 4.364 & -2.893 & -0.130 \\
\hline & (0.599) & (3.212) & $(2.350)$ & $(0.271)$ \\
\hline
\end{tabular}


Table 3

Continued.

\begin{tabular}{|c|c|c|c|c|}
\hline & Diagnostic test & $\begin{array}{l}\text { Attitude toward } \\
\text { learning }\end{array}$ & $\begin{array}{l}\text { Learning } \\
\text { behavior }\end{array}$ & $\begin{array}{l}\text { University } \\
\text { aspiration }\end{array}$ \\
\hline & Model 1 & Model 2 & Model 3 & Model 4 \\
\hline \multicolumn{5}{|l|}{ Controls (Science Ref Group) } \\
\hline \multirow[t]{2}{*}{ English } & -0.0396 & -0.122 & $-0.430^{*}$ & -0.00216 \\
\hline & $(0.0625)$ & $(0.331)$ & $(0.248)$ & (0.0293) \\
\hline \multirow[t]{2}{*}{ Math } & $0.446^{* * *}$ & -0.230 & -0.217 & $0.0765^{*}$ \\
\hline & $(0.118)$ & $(0.520)$ & $(0.372)$ & $(0.0437)$ \\
\hline \multirow[t]{2}{*}{ Constant } & $-2.550^{* * *}$ & $-1.83^{* * *}$ & -1.307 & $0.374^{* *}$ \\
\hline & (0.574) & -0.687 & -2.04 & -0.161 \\
\hline \multirow{2}{*}{$\begin{array}{l}\text { Variance of the constant (Level-2 } \\
\text { random effect) }\end{array}$} & 0.004 & 0.385 & 0.213 & 0.003 \\
\hline & $(0.001)$ & $(0.067)$ & $(0.037)$ & $(0.001)$ \\
\hline
\end{tabular}

${ }^{* * *} p<0.001 ;{ }^{* *} p<0.05 ;{ }^{*} p<0.1$; standard errors in parenthesis

Note: $N$ at the classroom level is $135 ; N$ at the teacher level is 27 .

practice would continuously work to improve their practice in relation to learning goals for their respective students. Hence, the positive and significant coefficient value for the ongoing variable is not surprising.

However, at the same time, multilevel regression results suggest that setting high expectations, challenging students through academic rigor, incorporation of student vision in lessons, caring for students, and valuing student input are negatively associated with end-of-year tests scores. These results are surprising, as one would expect these factors to be positively correlated with end-of-year test scores. These results do not necessarily suggest that these teacher behaviors directly lead to lower academic achievement as measured by test scores. Nevertheless, some potential explanations for these negative associations may be that students in Qatar's independent schools may lose motivation to engage in learning if they find that classwork is too difficult or challenging due to the teacher setting high expectations. Another reason may be that TDL teachers who incorporate their student vision into their lessons spend less time focusing on academic content but more on non-academic aspects of learning. This is a plausible reason given that the majority of TDL teachers' student visions are centered on attitudinal and behavioral student outcomes such as enjoying learning, valuing education and school, and fostering values such as respect in students (TDL, 2016a). If teachers spend a portion of their limited class time working on fostering values and mindsets in students, they may have limited time to teach curricular content in class. However, actual reasons and drivers for these negative relationships are uncertain. Further research and analysis are needed to provide a more robust (including causal) explanation for why and how these factors may be associated with lower test scores. 


\subsection{Students' attitude toward learning}

Models 2-4 show multilevel regression results for non-academic student outcomes variables: attitude toward school/learning, student learning behavior, and aspiration to attend university. As expected and consistent with results from Model 1, pretest results are significant and positive predictors for end-of-year scores along these three outcome variables.

In examining classroom-level attitude toward learning/school, regression results (Model 2) indicate that teachers who incorporate student vision in classroom practice and set expectations for their students are more likely to yield classrooms with better attitude toward learning/school. This is not surprising provided that much of TDL teachers' student visions include motivating students to learn and value education. This suggests that teachers who do make an explicit effort to talk about the importance of learning and education in the classroom do affect students' attitude toward school. At the student level, it appears that male classrooms experience more positive change in terms of attitude toward learning compared to female classrooms. Literature suggests that male students are not as engaged in the learning process as female students in the Arab Gulf, including Qatar (Lee, 2016; Ridge, 2014). Hence, what these results may be suggesting is that greater improvements in positive attitude toward learning and school may occur over the course of the school year in male classrooms compared to that in female classrooms.

Multilevel regression results from Model 3 show that teachers conferring input from students in the classroom and managing classroom behavior are positively associated with student learning behavior demonstrated at the classroom level. This is not surprising if classrooms with higher demonstrations of positive learning behavior would be associated with teachers who are able to manage the classroom and give students voice in the classroom by asking for input.

Model 4 examines average classroom-level aspirations to enroll in university. It appears that establishing positive student-teacher rapport is the only variable that is positively associated with classroom aspirations to attend university. Results also suggest that classrooms in which teachers challenge students through academic rigor are negatively associated with classroom-level aspirations for university. This, again, is surprising but could possibly be that students who feel that academic work is difficult or view that it is too demanding may be demotivated to pursue further education. This is plausible given the already low motivation and engagement levels of students to learn in addition to low demonstration of grit and perseverance in Qatar's independent schools (Lee, 2016; SESRI, 2013). Nevertheless, descriptive statistics suggest that there is not much variation between end-of-year and beginning-of-year aspirations for university, as over $95 \%$ of students express aspiration to enroll in university. Therefore, it is unsurprising to find that most teacher-level predictors are statistically insignificant compared to that in other models.

In examining all four models and their associated variables, regression results show that teachers practicing ongoing reflection is positive and significant in predicting 
classroom-level academic achievement but not students' attitude toward learning, learning behavior, and aspirations to attend university. This is surprising given that it would be expected that teachers who practice ongoing reflection improve practice across all areas of student outcomes, not just academic achievement. However, it may be easier for teachers to set specific goals for academic, subject-specific learning and work toward improving them, as assessments for academic learning are much more concrete than non-academic learning goals such as demonstrating active learning behavior, having positive attitude toward school, and aspiring to attend university. It is worth noting that TDL's teaching training and development program focuses heavily on encouraging its teachers to engage in ongoing reflection (TDL, 2016a). Given that ongoing reflection does positively contribute to academic achievement, TDL could consider working with teachers more specifically on reflecting on their own practice to consider how their actions influence student motivation, attitude, and values toward learning and education.

On the contrary, regression results find that incorporating student vision in teaching practice has a positive and significant relationship with having positive attitude toward learning and school but not academic achievement. In fact, multilevel regression results suggest that incorporation of student vision is negatively associated with end-of-year test scores. These mixed results suggest that intentionally incorporating student vision into the teaching practice may positively contribute toward fostering positive attitude toward learning in students. This is not surprising given that the majority of TDL teachers' student visions focus on mindsets and values and not necessarily on academic achievement of students. However, the negative association with test scores suggests that TDL teachers may be spending less time on academic content delivery because they are incorporating other aspects of student vision in their classrooms. Further research and qualitative examination will be needed to examine this situation. However, if this is true, it may benefit TDL to encourage its teachers to incorporate academic learning goals into the teachers' student vision as well.

With regards to more specific teacher actions, there does not appear to be a teacher action variable that is consistent across the four outcome variables of interest.

Teacher action variables that appear to be significant but with different directional implications across the student outcome areas is the "confer" variable, which is an indicator that measures how teachers encourage and value students' ideas and views by seeking and respecting students' thoughts, opinions, and input as part of the learning process based on the Student Tripod Survey (Ferguson, 2012). While the "confer" variable is positively associated with student learning behavior demonstrated in the classroom, it is negatively associated with end-of-year test scores. Although we cannot make causal claims, our finding suggests that it is possible for a teacher action to be associated with different student outcomes across areas. In other words, these results speak to the complex nature of the classroom, where one teacher action such as encouraging students' ideas and input could influence students to demonstrate positive learning behavior in the classroom but not lead to as much improved academic achievement than intended.

This study provides insights into the ways that certain teacher actions could influence student academic achievement and attitude toward learning. However, this study is 
limited in that causal inferences cannot be made with the data and how this study did not evolve extensive observations of teacher-student interactions aside from the authors partaking in observations with TDL teacher coaches to ensure that teachers were consistently being assessed on the TDL observation rubrics. Therefore, additional research that involves more extensive qualitative studies of teacher and student interactions and learning outcomes in the classroom in addition to other studies that involve experimental design (with a comparison group that is comprised of non-TDL teachers) would provide more robust insights into the analysis provided in this paper.

\section{Conclusion}

This paper investigated the relationship between progressive teaching practices promoted by TDL and the Global Network, that is, academic achievement and students' demonstration of learning behavior, attitude toward school/learning, and aspiration to attend university in the $7^{\text {th }}$ and $8^{\text {th }}$ grade classrooms of Qatar's independent schools. Findings suggest that there is variation in the ways in which different teacher practices encouraged by TDL, based on Global Network's global model, affect student academic outcomes in addition to students' attitude toward learning and aspirations for university. Incorporating a contextualized student vision in teacher practice, for example, appears to positively contribute to students' attitude toward learning/school but negatively contribute to student academic achievement. It also appears that more positive change in academic achievement is observed in classrooms where teachers engage in ongoing reflection to improve practice, but this teacher characteristic does not appear to have an influence on students' attitude toward learning and school and university aspirations.

These mixed results are surprising considering that all of these elements are expected to positively contribute toward student academic and non-academic outcomes. The mixed results, in addition to the limited scope of the data, make it difficult to ascertain the extent to which the Global Network model is applicable and/or appropriate for the Qatari context as implemented by TDL. Nevertheless, analysis finds that incorporating contextualized student vision in the classroom is important for non-academic outcomes in students such as fostering positive attitude toward learning and education. Furthermore, analysis also finds that engaging in ongoing reflection is a positive and significant predictor of academic achievement. These two teacher practices are ones that TDL has specifically drawn from the Global Network model and are what distinguishes TDL from teacher development provided in Qatar's independent schools.

These findings are particularly relevant for Qatar, and potentially the wider Arab Gulf's context, where large numbers of students do not value education or are not motivated to learn and where academic achievement in general is low (Ashcraft, 2007; Lee, 2016; Engin \& McKeown, 2012). Whether or not particular models of contextualized student vision and ongoing reflection as promoted by Global Network should be adopted in the Qatari public school and other similar contexts is debatable. Furthermore, the specific patterns and corresponding significant relationships found in this paper may be limited to TDL teachers' classrooms from 2015 to 2017. 
Nevertheless, the paper's findings are meaningful for teacher educators, school administrators, and policy makers, as it provides insights into specific teacher characteristics and actions that may positively contribute to student academic and nonacademic outcomes. More generally, teacher educators, administrators, and policy makers in Qatar, for example, could more explicitly integrate social constructivist and culturally relevant pedagogies and have teachers themselves engage in reflection and metacognitive practices in their teacher training programs and national teacher professional development standards. This may contribute to a cultural shift in teaching practices to be more student-centered and constructive and even allow for classrooms and schools to integrate Arabic heritage and culture into the learning process in deeper ways.

\section{Appendix}

\section{Table A1}

Descriptive statistics

Variable
End-of-year Diagnostic test score
End-of-year Learning Behavior Outcome factor score
End-of-year Attitude Toward School factor score
End-of-year \% of Students Who Want to Attend
University
Beginning-of-year Diagnostic test score
Beginning-of-year Learning Behavior Outcome factor
score
Beginning-of-year Attitude Toward School factor
score
Beginning-of-year \% of Students Who Want to Attend
University
Male
Qatari
English class
Math class
Teacher's Years of Experience
Setting High Expectations rubric score (5-point scale)
Differentiation rubric score (5-point scale)
Articulate Student Vision rubric score (5-point scale)
Student-Teacher Rapport rubric score (5-point scale)
Ongoing Reflection rubric score (5-point scale)
Care (Encourage)
Consolidate (Internalize)
Control (Classroom management)
Challenge (Rigor)
Confer (Input)
Clarify (Understanding)
Captivate (Engage)
(a)

\begin{tabular}{|c|}
\hline $\mathbf{N}$ \\
\hline 58 \\
\hline 114 \\
\hline 114 \\
\hline 114 \\
\hline 95 \\
\hline 127 \\
\hline 127 \\
\hline 127 \\
\hline 136 \\
\hline 136 \\
\hline 134 \\
\hline 134 \\
\hline 136 \\
\hline 136 \\
\hline 136 \\
\hline 118 \\
\hline 136 \\
\hline 131 \\
\hline 113 \\
\hline 114 \\
\hline 114 \\
\hline 114 \\
\hline 114 \\
\hline 114 \\
\hline
\end{tabular}

\begin{tabular}{|c|c|c|c|}
\hline Mean & Std. Dev. & Min. & Max. \\
\hline 0.488 & 0.185 & 0.11 & 0.9 \\
\hline 0.645 & 0.0936 & 0.38 & 0.86 \\
\hline 0.583 & 0.0901 & 0.324 & 0.798 \\
\hline 0.913 & 0.0768 & 0.67 & 1 \\
\hline 0.321 & 0.122 & 0.06 & 0.66 \\
\hline 0.693 & 0.0807 & 0.428 & 0.838 \\
\hline 0.661 & 0.094 & 0.39 & 0.9 \\
\hline 0.917 & 0.077 & 0.64 & 1 \\
\hline 0.243 & 0.430 & 0 & 1 \\
\hline 0.338 & 0.475 & 0 & 1 \\
\hline 0.231 & 0.423 & 0 & 1 \\
\hline 0.381 & 0.487 & 0 & 1 \\
\hline 1.426 & 0.496 & 1 & 2 \\
\hline 3.085 & 0.663 & 2 & 4 \\
\hline 2.000 & 0.933 & 1 & 4 \\
\hline 3.004 & 0.729 & 2 & 5 \\
\hline 3.423 & 0.704 & 2 & 5 \\
\hline 4.878 & 0.329 & 4 & 5 \\
\hline 0.559 & 0.160 & 0.19 & 0.94 \\
\hline 0.647 & 0.180 & 0.2 & 0.97 \\
\hline 0.694 & 0.153 & 0.37 & 0.97 \\
\hline 0.597 & 0.155 & 0.28 & 0.94 \\
\hline 0.662 & 0.156 & 0.27 & 0.96 \\
\hline 0.595 & 0.184 & 0.13 & 0.98 \\
\hline 0.475 & 0.140 & 0.18 & 0.82 \\
\hline & & & \\
\hline
\end{tabular}




\section{Authors' Biographies}

Seungah S. Lee is a PhD candidate at Stanford University studying International Comparative Education and Organizational Studies. Her research focuses on the interplay between youth development, entrepreneurship, and innovation as part of the wider national development agenda. Prior to her doctoral studies, she worked in the Middle East designing teacher leadership programs, leading program evaluation efforts, and building monitoring and evaluation systems.

Leena Zahir is an independent researcher and education consultant based in Doha, Qatar. She has experience implementing monitoring and evaluation systems, conducting program evaluation, and consulting on various education research and programs. Leena holds a BSFS from Georgetown Unviersity-Qatar and an Ed.M. in International Education Policy from Harvard University.

\section{Author Contributions}

Seungah S. Lee (first author) made substantial contributions to this work by leading the conception and design of the work. She was involved in acquisition, analysis, and interpretation of data for the work, drafting the work and revising it critically for intellectual content, and gave final approval of the version to be submitted for publication. She is willing to be accountable for all aspects of the work in ensuring that questions related to the accuracy or integrity of any part of the work are appropriately investigated and resolved.

Leena Zahir (second author) made substantial contributions to this work by being involved from the conception and design of the work. She was involved in the acquisition, analysis, and interpretation of data for the work in addition to drafting and revising the work towards publication. She is willing to be accountable for all aspects of the work in ensuring that questions related to the accuracy or integrity of any part of the work are appropriately investigated and resolved.

\section{Acknowledgements}

The authors would like to thank the staff and teachers of TDL who provided their data to us in addition to the students, teachers, and school administrators in Qatar's public schools who participated in this study.

\section{Funding Information}

This research did not benefit from any funding source at any stage of writing this paper.

\section{Competing Interests}

The author have no competing interests to declare. 


\section{References}

[1] Abu-Tineh, A. M., \& Sadiq, H. M. (2018). Characteristics and models of effective professional development: The case of school teachers in Qatar. Professional Development in Education, 44(2), 311-322

[2] Ackerman, E. (2001). Piaget's constructivism, Papert's constructionism: What's the difference? Retrieved from http://learning.media.mit.edu/content/publications/EA.Piaget\%20_\%20Papert.pdf

[3] Ahmann, C. (2015). Teach for all: Storytelling "shared solutions" and scaling global reform. Education Policy Analysis Archives, 23(45).

[4] Al-Fadala, A. (2015). K-12 Reform in the Gulf Cooperation Council (GCC) Countries: Challenges and Policy Recommendations. The World Innovation Summit for Education (WISE).

[5] Alkhater, L. R. M. (2016). Qatar's borrowed K-12 education reform in context. In M. E. Tok, L. R. M. Alkhater, \& L. A. Pal (Eds.), Policy-making in a Transformative State: The Case of Qatar (pp. 97-130). Palgrave Macmillan.

[6] Al Thani, M. (2012). The Arab Spring \& the Gulf states: Time to embrace change. Profile Books.

[7] Ashcraft, N. (2007). UAE pre-service teachers' motivations for entering the world of TESOL. In L. Stephenson \& P. Davidson (Eds.), Teacher Education and Continuing Professional Development: Insights from the Arabian Gulf (pp. 27-42). Arabia: TESOL.

[8] Lee, S. (2016). What motivates and engages students in the education process: An examination of Qatari students' mindset and attitudes toward going to school, learning, and future aspirations. Journal of Education and Learning, 5(3), 220-235.

[9] Badry, F., \& Wiloughby, J. (2016). Higher Education Revolutions in the Gulf: Globalization and Institutional Viability. Routledge.

[10] Barber, M., Mourshed, M., \& Whelan, F. (2007). Improving education in the Gulf McKinsey Quarterly. Retrieved from http://www.mckinseyquarterly.com/Improving_education

[11] Bransford, J. D., Brown, A. L., \& Cocking, R. (Eds.) (1999). Effective teaching: Examples in history, mathematics, and science. In How People Learn: Brain, Mind, Experience, and School (pp. 143-177). National Research Council.

[12] Brewer, D. J., Augustine, C. H., Zellman, G. L., Ryan, G., Goldman, C. A., Stasz, C., \& Constant, L. (2007). Education for a New Era: Design and Implementation of K-12 Education Reform in Qatar. RAND Corporation.

[13] Cheema, J. R. (2015). The private-public literacy divide amid educational reform in Qatar: What does PISA tell us? International Review of Education, 61(2), 173-189.

[14] Chi, M. T., Leeuw, N., Chiu, M. H., \& LaVancher, C. (1994). Eliciting self囚explanations improves understanding. Cognitive Science, 18(3), 439-477.

[15] Cumsille, R., \& Fiszbein, A. (2015). Crème de la Crème: The teach for all experience and its lessons for policy-making in Latin America. Education Policy Analysis Archives, 23(46), 1-26.

[16] De Boer, K., \& Turner, J. M. (2007). Beyond oil: Reappraising the Gulf States. The McKinsey Quarterly. Retrieved from https://yaleglobal.yale.edu/content/beyond-oil-reappraising-gulf-states

[17] Driouchi, A., \& Gamar, A. (2016). The gap between educational \& social intergenerational mobility in Arab Countries. Munich Personal RePEc Archive. Retrieved from https://mpra.ub.uni-muenchen.de/73998/

[18] Ellili-Cherif, M., Romanowski, M. H., \& Nasser, R. (2012). All that glitters is not gold: Challenges of teacher and school leader licensure licensing system in Qatar. International Journal of Educational Development, 32(3), 471-481.

[19] Ellis, V., Maguire, M., Trippestad, T. A., Liu, Y., Yang, X., \& Zeichner, K. (2015). Teaching other people's children, elsewhere, for a while: The rhetoric of a travelling educational reform. Journal of Education Policy, 31(1), 60-80.

[20] Engin, M., \& McKeown, K. (2012). Cultural influences on motivational issues in students and their goals for studying at university. Learning and Teaching in Higher Education: Gulf Perspectives, 9(1).

[21] Farr, S. (2010). Teaching as Leadership the Highly Effective Teachers Guide to Closing the Achievement Gap. San Francisco, CA: Jossey-Bass.

[22] Ferguson, R. F. (2012). Can student surveys measure teaching quality? Phi Delta Kappan, 94(3), 24-28.

[23] Global Network. (2019). Global network: An overview. Internal document: unpublished.

[24] Gredler, M. (Ed.). (1997). Early learning theories. In Learning and Instruction (pp. 36-67). Pearson.

[25] Gredler, M. (Ed.). (2009). What is the philosophy referred to as constructivism? In Learning and Instruction: Theory into Practice $\left(6^{\text {th }}\right.$ ed., pp. 19-26). Pearson.

[26] Ingersoll, R. M., \& Collins, G. J. (2018). The status of teaching as a profession. In J. Ballantine, J. Spade, \& J. Stuber (Eds.), Schools and Society: A Sociological Approach to Education (6 $6^{\text {th }}$ ed., pp. 199-213). Pine Forge Press/SAGE Publications. 
[27] Knight, S. L., Parker, D., Zimmerman, W., \& Ikhlief, A. (2014). Relationship between perceived and observed student-centered learning environments in Qatari elementary mathematics and science classrooms. Learning Environments Research, 17(1), 29-47.

[28] Ladson-Billings, G. (Ed.). (1994). Trees of knowledge \& culturally relevant teaching. In The Dreamkeepers (pp. 78-126). Jossey Bass.

[29] Ladson-Billings, G. (1995a). But that's just good teaching! The case for culturally relevant pedagogy. Theory into Practice, 34(3), 159-165.

[30] Ladson-Billings, G. (1995b). Toward a theory of culturally relevant pedagogy. American Educational Research Journal, 32(3), 465.

[31] McConney, A., Price, A., \& Woods-McConney, A. (2012). Fast Track Teacher Education: A Review of the Research Literature on Teach for All Schemes. Centre for Learning, Change and Development School of Education Murdoch University. Retrieved from https://files.eric.ed.gov/fulltext/ED529919.pdf

[32] Mullis, L. V., Martin, M., \& Foy, P. (2012). Trends in International Mathematics and Science Study (TIMSS) 2011 International Results in Mathematics. International Association for the Evaluation of Educational Achievement.

[33] Nasser, R. (2017). Qatar's educational reform past and future: Challenges in teacher development. Open Review of Educational Research, 4(1), 1-19.

[34] Nasser, R., \& Romanowski, M. H. (2011). Teacher perceptions of professional development in the context of national educational reform: The case of Qatar. International Journal of Training and Development, 15(2), 158-168.

[35] OECD. (2014). PISA 2012 results in focus: What 15-year Olds Know and What They Can Do With What They Know. OECD. Retrieved from https://www.oecd.org/pisa/keyfindings/pisa-2012-results-overview. pdf

[36] Papert, S. (2000). What's the big idea? Toward a pedagogy of idea power. IBM Systems Journal, 39(3.4), 720-729. https://doi.org/10.1147/sj.393.0720

[37] Qatar Ministry of Education. (2015-2016). National Professional Standards for Teachers and Leaders. Retrieved from https://csoscience.files.wordpress.com/2010/10/npst-overview-arabic.doc

[38] Raudenbush, S. W., \& Byrk, A. S. (2002). Hierarchical Linear Models: Applications and Data Analysis Methods. SAGE Publications.

[39] Ridge, N. (2014). Education and the Reverse Gender Divide in the Gulf States: Embracing the Global, Ignoring the Local. Teachers College Press.

[40] SESRI. (2013). Qatar Education Study 2012: Students' Motivation and Parental Participation Report. Doha: Qatar University.

[41] Sherman, S. (2009). Haven't we seen this before? Sustaining a vision in teacher education for progressive teaching practice. Teacher Education Quarterly, 36(4), 41-60.

[42] Skinner, B. F. (1986). Programmed instruction revisited. Phi Delta Kappan, 68(2), 103-110.

[43] TDL. (2015). Overview of TDL. Internal document: unpublished.

[44] TDL. (2016a). Theory of Change, Impact \& Evaluation Strategy. Internal document: unpublished.

[45] TDL. (2016b). Observation Rubric for TDL Classroom. Internal document: unpublished.

[46] Thorndike, E. (Ed.). (1913). Associative learning in man: Varieties in learning. In The Psychology of Learning (pp. 17-31). Columbia University Press.

[47] Wiske, M. S. (1998). What is Teaching for Understanding? In M. S. Wiske (Ed.), Teaching for Understanding (pp. 61-87). Jossey-Bass.

[48] Zellman, G. L., Ryan, G. W., Karam, R., Constant, L., Salem, H., Gonzalez, G., ... Al-Obaidli, K. (2009). Implementation of the K-12 Education Reform in Qatar's Schools. RAND Corporation. 